\title{
Removal of Noxious Cr (VI) and Cr (III) Ions by Hierarchically Tailored Pseudo-Monolithic Silica/Activated Carbon Composite
}

\author{
Saad Melhi' ${ }^{1}$, Saeed Ullah Jan ${ }^{2 *}$, Faiz Ali ${ }^{2}$, Muhammad Absar Kan ${ }^{3}$, Sana Begum ${ }^{3}$, Khan Badsha ${ }^{2}$ and Muhammad \\ Sufaid Khan ${ }^{2}$ \\ ${ }^{1}$ Department of Chemistry, College of Science, University of Bisha, Bisha, 61922, Saudi Arabia \\ ${ }^{2}$ Department of Chemistry, Chakdara Lower Dir, 18800, University of Malakand, Pakistan
}

${ }^{3}$ Faculty of Basic and Applied Sciences, University of Poonch Rawalakot, AJK, Pakistan

*Corresponding Author: Saeed Ullah Jan, Department of Chemistry, Chakdara Lower Dir, 18800, University of Malakand, Pakistan.

Received: December 13, 2021; Published: January 03, 2022

\begin{abstract}
In the present study, $2.34 \mathrm{~m}$ (average) silica particles with large pore size (363 Å) have been prepared from bulk monoliths by using sol-gel method and were then chemically modified by reaction with a C-18 and was used for the adsorption of Cr (VI) and $\mathrm{Cr}$ (III) ions from wastewater. The prepared adsorbent was characterized by Scanning electronic microscope (SEM) and X-ray Diffraction (XRD) analysis before and after the adsorption of Cr (III) and Cr (VI) ions. The amount of Cr (III) and Cr (VI) adsorbed was detected by Atomic Absorption spectroscopy (AAS). The $90 \% \mathrm{Cr}$ (VI) and $98 \% \mathrm{Cr}$ (III) were achieved at pH3 and, 6 respectively. The process followed pseudo $2^{\text {nd }}$ order kinetics, Langmuir and Freundlich isotherms well. The $\Delta \mathrm{G}$ values were -50.02 and $-49.62 \mathrm{~kJ} \mathrm{~mol}^{-1}$, for $\mathrm{Cr}(\mathrm{VI})$ ions and $\mathrm{Cr}(\mathrm{III})$ ions respectively, which show spontaneous adsorption of $\mathrm{Cr}(\mathrm{VI})$ and $\mathrm{Cr}(\mathrm{III})$ ions on to AC surface. $\Delta \mathrm{H}$ was $44.18 \mathrm{~kJ} \mathrm{~mol}^{-1}$ for $\mathrm{Cr}(\mathrm{VI})$ and $39.55 \mathrm{~kJ} \mathrm{~mol}^{-1 \text { " }}$ for $\mathrm{Cr}(\mathrm{III})$ ions, are showing the endothermic nature of adsorption. The $\Delta \mathrm{S}\left(152 \mathrm{~J} \mathrm{~mol}^{-1} \mathrm{~K}^{-1}\right.$ for $\mathrm{Cr}(\mathrm{VI})$ and $139.88 \mathrm{~mol}^{-1} \mathrm{~K}^{-1}$ for $\mathrm{Cr}(\mathrm{III})$ ions) showing sorbate/sorbent complex stability. Keywords: Pseudo Monolithic Silica; SEM; XRD; Atomic Adsorption Spectroscopy
\end{abstract}

\section{Introduction}

Chromium, the most widely used metal helps in protecting materials from environmental degradation. About $80 \%$ of the mined chromium goes into metallurgical application. About $15 \%$ is used in chromium chemicals and the remaining is used in refractory application. Chromium compounds have wide application in leather tanning, dyes, wood preservation, welding batteries and catalysts [1]. Although $\mathrm{Cr}$ (III) is nutritionally essential in trace quantities, however $\mathrm{Cr}$ (VI) have deleterious effects on eyes, liver, kidney, respiratory and gastrointestinal tract and skin. Lung cancer has been reported in workers dealing with chromate [2]. Water is being continuously contaminated with chromium and its compound from industrial effluents and mining run off. Chromium contamination of water bodies must be abated to save the plants and animals from the harmful effects of chromium especially in the hexavalent state. Various methods such as reduction and precipitation, ion exchange, electrolysis and electroplating and adsorption have been used for the removal of chromium from water. Sorption is considered superior over other techniques because of its higher efficiency, low cost and simple operation [3]. Chromium, an important element from environmental point of view has been the subject of several studies wherein its accumulation on cheaper materials like flyash wollastonite [4], zeolites [5], modified coconut husk [6], rice husk [7], Haro river sand [8], seed of leguminous crops [8] and modified rice husks [9] have been investigated. Chromium pollution is a serious problem facing our country due to the tannery industry. Therefore a comprehensive and low cost sorbent is needed for the removal of 
chromium [10,11]. Due to extensive industrialization, the quality of water is highly compromised [11]. The heavy metals ions, released by different industries is an emerging water pollution [12]. Chromium is important heavy metal occurs in nature in six oxidation states (I-VI) [10]. The main causes of Cr(VI) availability/presence in water are industrial disposals and weathering of chromite rocks; the different industries that release chromium are leather tanning, electroplating and batteries [12, 13]. $\mathrm{Cr}$ (III) is essential for humans and its deficiency may cause diabetes [14] while $\mathrm{Cr}(\mathrm{VI})$ has noxious effects on the gastrointestinal tract, kidneys, liver, and is carcinogenic and mutagenic to humans [15]. Theermissible level of $\mathrm{Cr}$ (VI) is less than 0.005 and $0.10 \mathrm{mg} \mathrm{dm}^{-3}$ for drinking and industrial wastewater respectively $[16,17]$. It is vital for human health and environmental safety to ascertain $\mathrm{Cr}$ (VI) concentration in the environment on regular basis and develop techniques for the capturing of $\mathrm{Cr}$ (VI) ion, before it is discharged into water bodies. In water $\mathrm{Cr}(\mathrm{VI})$ is present in oxyanions forms i.e. $\mathrm{CrO}_{4}{ }^{2-}$ and $\mathrm{Cr}_{2} \mathrm{O}_{7}{ }^{2-}$ which adsorbs onto various adsorbents at low $\mathrm{pH}$ [12].

Several separation techniques like ion exchange, reverse osmosis, chemical precipitation, electrolytic extraction and redox method have been designed and applied for the scavenging of heavy metals. However, these methods have their limitations e.g., long processing time, high energy consumption and poor sequestration [18]. Adsorption is an efficient technique as it is simple in operation, cost-effective and environment friendly [19]. A variety of adsorbents like silica gel [20, 21], clay [22, 23] and (bio-adsorbents) [24] have already been reported for the sequestration of heavy metals. Herein, $2.34 \mathrm{~m}$ (average) silica particles with large pore size (363 $\AA$ ) have been prepared from bulk monoliths by using sol-gel method. The scale of silica monolith production of this study was increased by three times as compared to the previous method, The resultant silica monolith particles were then chemically modified by reaction with a $\mathrm{C}-18$ and was used for the adsorption of $\mathrm{Cr}(\mathrm{VI})$ and $\mathrm{Cr}(\mathrm{III})$ ions from waste water.

\section{Experimental Section}

Regents and Materials

Glacial Acetic Acid, urea, PEG (Polyethylene glycol), trimethyl ortho silicate (TMOS), Toluene, and 3-Aminopropyle - triethoxysilane (APS) was obtained from (Sigma Aldrich).Salts of Cr (VI) and Cr (III) were purchased from (Merck). Methanol, Acetonitrile, Acetone were used of analytical grade.

\section{Instrumentation}

The Atomic Absorption Spectrophotometer (AAS) was used to determine the $\mathrm{Cr}$ (VI) and Cr (III) ions concentration in solution before and after adsorption. Synthesized AC/monolith-SiO ${ }_{2}$ was characterized by XRD; Shimadzu Model (6000) for crystallinity.

The surface morphology and microstructure of the newly prepared AC/monolith-SiO 2 were explored by means of Field Emission Scanning Electron Microscope (FESEM, FEI Nova-Nano SEM-600).

\section{Synthesis of Silica Monolith particles}

The synthetic route for the preparation of silica monoliths was modified to get smaller $(2.34 \mathrm{~m})$ silica monolith particles with larger pores. The amount of PEG and urea were further increased with respect to TMOS, and the relative amount of catalytic solvent (dilute acetic acid) was also increased. Thus, $4000 \mathrm{mg}$ PEG and $4125 \mathrm{mg}$ urea were dissolved in $36 \mathrm{~mL} 0.01 \mathrm{M}$ acetic acid. A $10 \mathrm{~mL}$ aliquot of TMOS was added to the solution in an Ice/water condition and stirred for $60 \mathrm{~min}$. The solution was gelled at $40 \mathrm{C}^{\circ}$ in an oven for 48 $\mathrm{h}$, and aged at $120 \mathrm{C}^{\circ}$ in an autoclave for $48 \mathrm{~h}$. The residual water was decanted off and the silica monolith was dried at $70 \mathrm{C}^{\circ}$ for $20 \mathrm{~h}$, ground with a mortar and pestle for $10 \mathrm{~min}$, and calcined at $550 \mathrm{C}^{\circ}$ for $50 \mathrm{~h}$ [25].

\section{Results and Discussion}

Characterization of AC/monolith-SiO ${ }_{2}$ surface by Scanning Electron Microscopy (FE-SEM)

The surface morphology of $\mathrm{AC} /$ monolith- $\mathrm{SiO}_{2}$ composite before and after adsorption of $\mathrm{Cr}$ (VI) and Cr (III) was analysed by using scanning electron microscopy (1000 KV) using magnification power of 100,000 and the scale bar was $500 \mathrm{~nm}, 1 \mu \mathrm{m}$ and $2 \mu \mathrm{m}$ as 


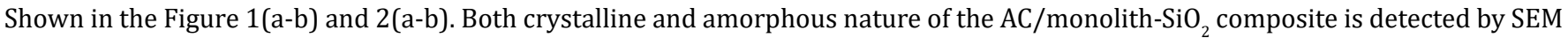
micrograph [25]. The SEM images revealed that the $\mathrm{AC} / \mathrm{monolithSiO}_{2}$ composite surface is very rough in Figure $1 \mathrm{a}$ and Figure $1 \mathrm{bbefore}$ adsorption of the metal ions and after adsorption of $\mathrm{Cr}$ (VI) and $\mathrm{Cr}$ (III) ions the surface becomes smooth as shown in Figure 2a and Figure $2 \mathrm{~b}$, which reveal that the metals ions have been effectively adsorbed on the surface of adsorbent.
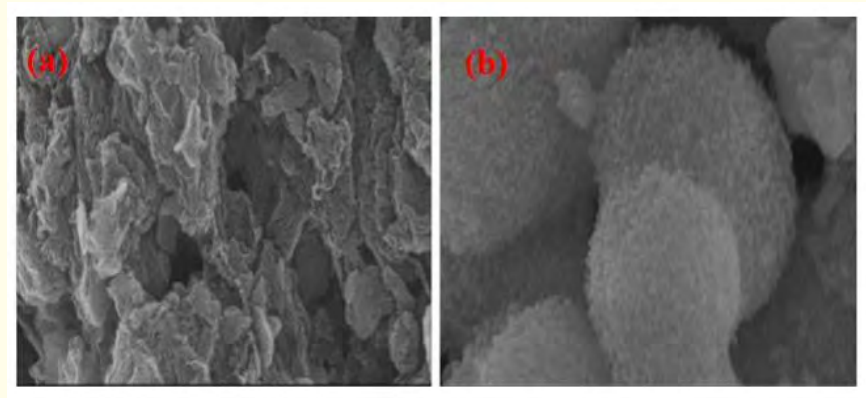

Figure 1a and 1b: FE-SEM images of $\mathrm{AC} /$ monolith-SiO $_{2}$ surface before adsorption.
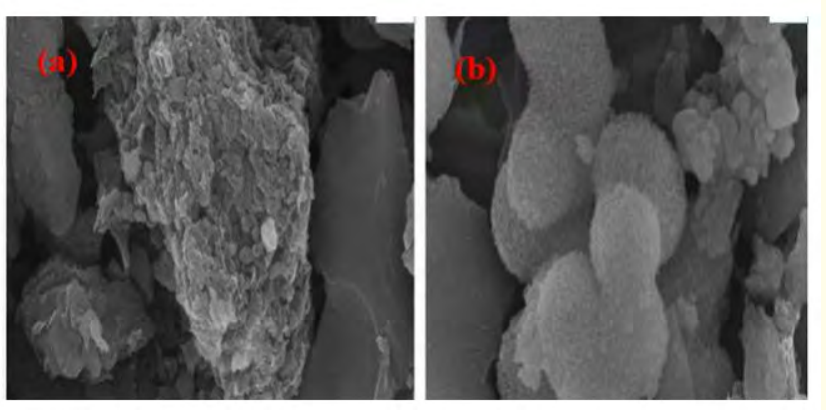

Figure 2a and 2b: FE-SEM images of $\mathrm{Cr}(\mathrm{VI})$ and $\mathrm{Cr}(\mathrm{III})$ loaded $\mathrm{AC} /$ monolith $-\mathrm{SiO}_{2}$.

\section{$\mathrm{X}$-ray diffraction studies of the $\mathrm{AC} /$ monolith- $\mathrm{SiO}_{2}$}

Figures 3a shows XRD patterns of the $\mathrm{AC} /$ monolith- $\mathrm{SiO}_{2}$ composite before the adsorption of $\mathrm{Cr}(\mathrm{VI})$ and $\mathrm{Cr}(\mathrm{III}) \mathrm{metal}$ ions. Broad peak of the adsorbent is observed in the region between 20 and 30 shown by XRD.

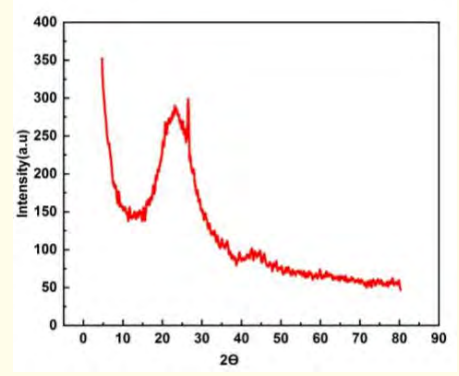

Figure 3a: XRD pattern $\mathrm{AC} /$ monolith- $\mathrm{SiO}_{2}$ produced before the adsorption of $\mathrm{Cr}(\mathrm{VI})$. 
While the peaks obtained for chromium metal ion from XRD pattern after adsorption of $\mathrm{Cr}$ (VI) and Cr(III) are shown in Figure 3b and $3 c$ respectively. Significant difference is not observed in the nature of the composite before and after adsorption which means that the composite form in this study is very stable [25]. Recently form $\mathrm{AC} /$ monolith-SiO ${ }_{2}$ composite exhibit different properties such as Composition and physical properties were determined by means of XRD pattern [26].

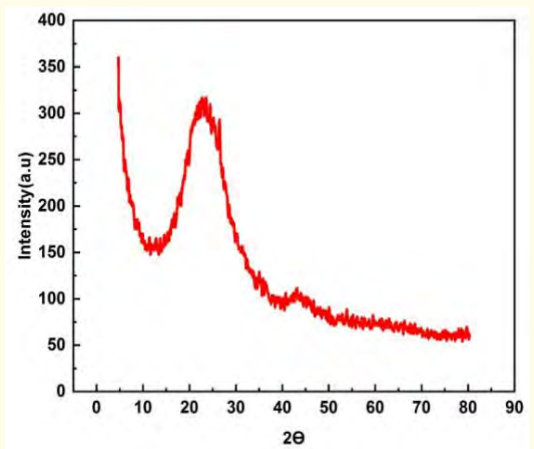

Figure 3b: XRD pattern of $\mathrm{Cr}(\mathrm{VI})$ and $\mathrm{Cr}(\mathrm{III})$ ions loaded $\mathrm{AC} /$ monolith- $\mathrm{SiO}_{2}$.

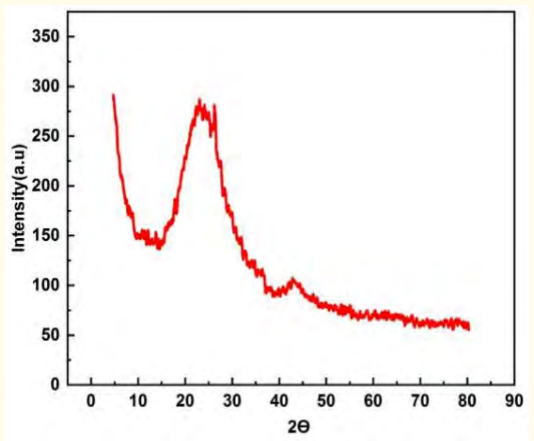

Figure 3c: XRD pattern of $\mathrm{AC} /$ monolith-SiO 2 after the adsorption of $\mathrm{Cr}(\mathrm{III})$.

\section{PH effect}

Adsorption of $\mathrm{Cr}$ (VI) and $\mathrm{Cr}(\mathrm{III})$ metal ions on $\mathrm{AC} /$ monolith-SiO ${ }_{2}$ composite is known to be strongly dependent on pH value of solution [27]. Complete removal of $\mathrm{Cr}$ (III) was observed at pH 6 (Figure 4) while Cr(VI) exhibited improved adsorption at pH 3 (Figure 4). A clear increment in adsorption rate was observed for $\mathrm{Cr}$ (VI) and $\mathrm{Cr}$ (III) at pH 3 and pH 6 respectively. 


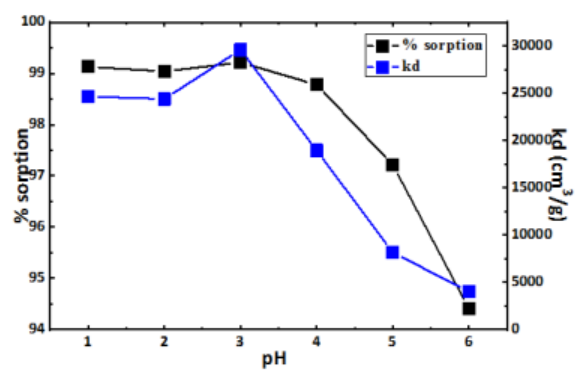

Figure 4: Plot for the adsorption of $\mathrm{Cr}(\mathrm{VI})$ at different $\mathrm{pH}$.

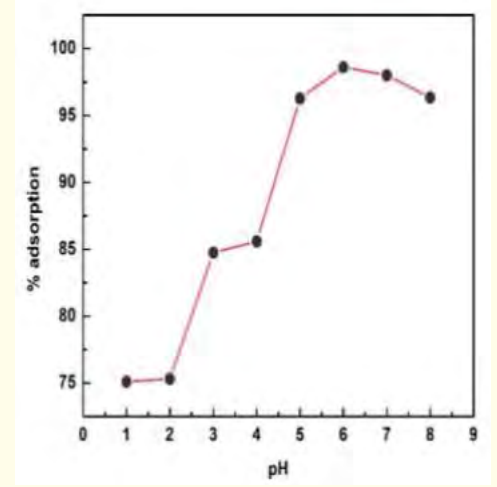

Figure 5: Plot for the adsorption of $\mathrm{Cr}(\mathrm{III})$ at different $\mathrm{pH}$.

\section{Effect of concentration}

Adsorption of $\mathrm{Cr}(\mathrm{VI})$ and $\mathrm{Cr}$ (III) metal ions heavily dependent on their concentrations [27]. The adsorption were studied at different metal ions concentrations starting from $20 \mathrm{ppm}$ to $160 \mathrm{ppm}$ The results indicated that the percent removal of $\mathrm{Cr}(\mathrm{VI})$ and $\mathrm{Cr}(\mathrm{III})$ increased initially with increased the initial concentration ranging from 20 ppm to $60 \mathrm{ppm}$. Considerable change was observed from 70 to 160 ppm showing no further increase in percent removal, so, to study others parameters 70 ppm was selected as optimized concentration values.

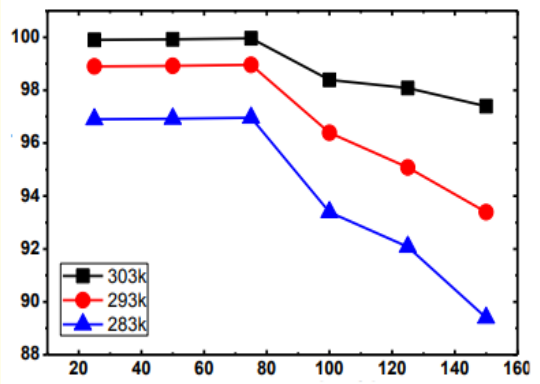

Figure 6: Plot for the adsorption of $\mathrm{Cr}(\mathrm{III})$ at different ppm. 


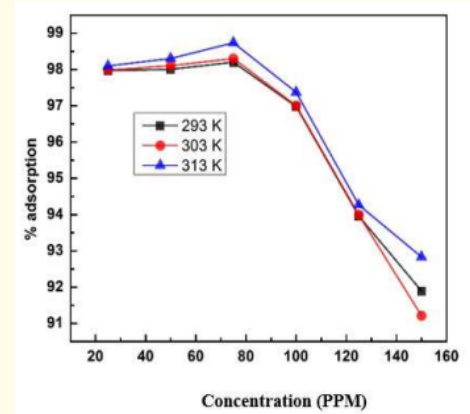

Figure 7: Plot for the adsorption of $\mathrm{Cr}(\mathrm{VI})$ at different ppm.

Experimental data was tested "by applying Langmuir" [28] and Freundlich Isotherm [29] to know the mechanism of adsorption.

The Langmuir equation was applied as;

$$
\frac{C_{e}}{q_{e}}=\frac{C_{e}}{Q_{\max }}+\frac{1}{K_{L} Q_{\max }}
$$

Where, $\mathrm{q}_{\mathrm{e}}$ represents equilibrium sorption, $\mathrm{Q}_{\max }$ is adsorption capacity at maximum (9.08 and $9.89 \mathrm{mg} \mathrm{g}^{-1}$ for $\mathrm{Cr}(\mathrm{VI})$ ions and $\mathrm{Cr}(\mathrm{III})$ ions respectively) and $\mathrm{K}_{\mathrm{L}}$ is the adsorption intensity (Figure 8a). RL is a constant which indicates the possibility of a process to occur [30]. Its value is deduced by the following relation [31].

$$
R_{L}=\frac{1}{1+K_{L} C_{e}}
$$

The $\mathrm{R}_{\mathrm{L}}$ values are 0.0014 and 0.0013 for $\mathrm{Cr}(\mathrm{VI})$ ions ion and $\mathrm{Cr}(\mathrm{III})$ ions respectively, which denote favourable adsorption. Freundlich isotherm [32] in the following equation gave further information about the mechanism of adsorption.

$$
\log q_{e}=\log K_{F}+\frac{1}{n} \log C_{e}
$$

Here, $\mathrm{K}_{\mathrm{F}}$ denotes sorption volume and $1 / \mathrm{n}$ reflects the heterogeneity of the surface calculated from Figure $8 \mathrm{~b}($ Table. 1 ). Results reveal the chemisorptions and spontaneous accumulation of $\mathrm{Cr}(\mathrm{VI})$ ions and $\mathrm{Cr}(\mathrm{III})$ ions over the adsorbent surface [33].

(a)

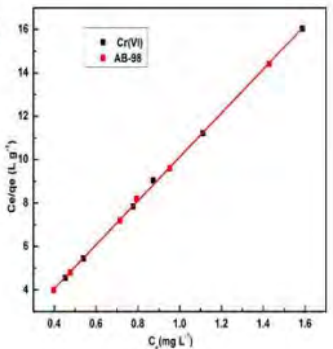

(b)

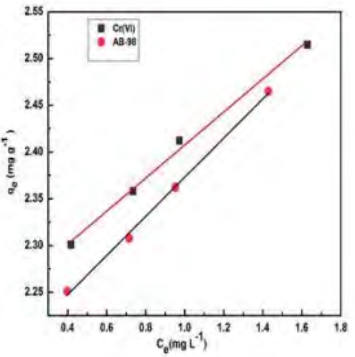

Figure 8 (a): Langmuir isotherm and (b) Freundlich of $\mathrm{Cr}(\mathrm{VI})$ and $\mathrm{Cr}(\mathrm{III})$ ions onto AC. 


\begin{tabular}{|c|c|c|c|c|c|c|}
\hline \multirow{3}{*}{ Langmuir parameters } & \multicolumn{6}{|c|}{ Temperature (K) } \\
\hline & \multicolumn{2}{|r|}{283} & \multicolumn{2}{|c|}{293} & \multicolumn{2}{|c|}{303} \\
\hline & $\mathrm{Cr}(\mathrm{VI})$ & Cr(III) IONS & Cr(VI) -Ion & Cr(III) IONS & Cr(VI) Ion & Cr(III)IONS \\
\hline $\mathrm{Q}_{\max } \cdot\left(\mathrm{mgg}^{-1}\right)$ & 9.08 & 9.89 & 9.1 & 9.93 & 9.97 & 9.97 \\
\hline $\mathrm{K}_{\mathrm{L}}\left(\mathrm{mmol} \cdot \mathrm{L}^{-1}\right)$ & 6.15 & 6.35 & 6.07 & 6.22 & 6.09 & 6.32 \\
\hline $\mathrm{R}_{\mathrm{L}}\left(\mathrm{L} \mathrm{mg}^{-1}\right)$ & 0.0014 & 0.0013 & 0.001 & 0.0012 & 0.0014 & 0.0015 \\
\hline $\mathrm{R}^{2}$ & 0.995 & 0.999 & 0.998 & 0.998 & 0.996 & 0.999 \\
\hline \multicolumn{7}{|c|}{ Freundlich parameters } \\
\hline $\mathrm{K}_{\mathrm{F}}\left(\mathrm{mmolg}^{1}\right)$ & 145.81 & 132.09 & 146.11 & 122.98 & 170.22 & 145.22 \\
\hline $1 / n$ & 0.209 & 0.099 & 0.210 & 0.098 & 0.210 & 0.099 \\
\hline $\mathrm{R}^{2}$ & 0.995 & 0.997 & 0.997 & 0.998 & 0.996 & 0.995 \\
\hline
\end{tabular}

Table 1: Langmuir and Freundlich models data of $\mathrm{Cr}$ (VI) and $\mathrm{Cr}$ (III) ions mixture.

\section{Effect of adsorbent dose}

The dose of the adsorbent (AC/monolith-SiO 2 composite) was varied from 0.01-0.05g to carry out the adsorption process for the removal of $\mathrm{Cr}$ (VI) and Cr (III) metal ion. keeping all the other experimental variables constant such as volume of the solution was 70 $\mathrm{mL}$, contact time (40 min), optimized metal concentration (70 ppm), pH (6) and (3) respectively for Cr(VI) and Cr(III) (already optimized) and at $25^{\circ} \mathrm{C}$. It was found that initially on increasing the adsorbent weight from 0.01 to $0.03 \mathrm{~g}$ percentage removal of $\mathrm{Cr}(\mathrm{VI})$ and $\mathrm{Cr}$ (III) gradually increases and on further increment there was no further improvement in terms of adsorption rate as shown in Figure 9 and Figure 10. Due the availability of a large number of binding sites for the incoming $\mathrm{Cr}(\mathrm{VI})$ and $\mathrm{Cr}$ (III) on adsorbent surface High adsorbent dosages results aggregation therefore further increment in adsorbent dose constant adsorption is maintained [34].

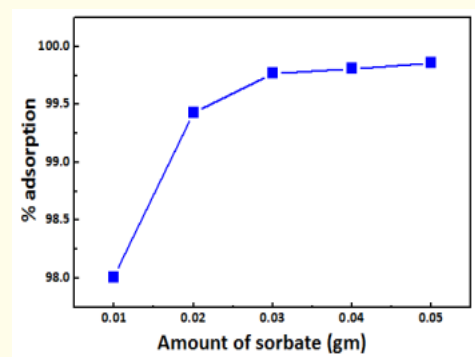

Figure 9: Plot for the \% removal of Cr (III) at different adsorbent dose.

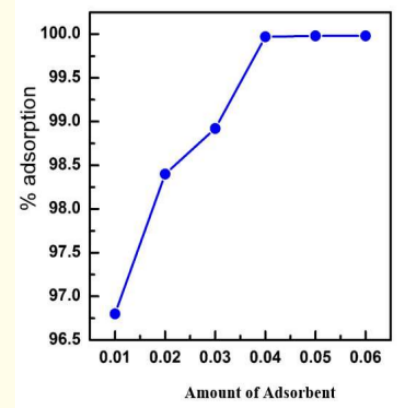

Figure 10: Plot for the removal of $\mathrm{Cr}(\mathrm{VI})$ at different adsorbent dose. 


\section{Effect of contact time}

Contact time is an important factor to determine the equilibrium time that should be permitted for the maximum uptake of an adsorptive by $\mathrm{AC} /$ monolith- $\mathrm{SiO}_{2}$ composite [35]. The time was adjusted at various intervals from 1 to 45 and 1-50 minutes to check the effect of contact time on the adsorption of $\mathrm{Cr}(\mathrm{VI})$ and $\mathrm{Cr}(\mathrm{III})$ respectively. The remaining experimental conditions such as concentration (80ppm), pH (3 and 6), and adsorbates dose of $0.04 \mathrm{~g}$ for both $\mathrm{Cr}$ (III) and $\mathrm{Cr}(\mathrm{VI})$. The rate of uptake was very faster in first 5 minute for both mentioned forms of $\mathrm{Cr}$ and maximum \% removal was achieved within 30-40 minutes.

\section{Kinetic Modelling}

The kinetic studies of adsorption described detailed information regarding the removal of $\mathrm{Cr}(\mathrm{VI})$ and $\mathrm{Cr}(\mathrm{III})$ on $\mathrm{AC} / \mathrm{monolith}^{-\mathrm{SiO}}{ }_{2}$ composite and to determine the controlling mechanism of the adsorption process. Different kinetic models were used to analyse the adsorption data such as pseudo-first-order and pseudo-second-order.

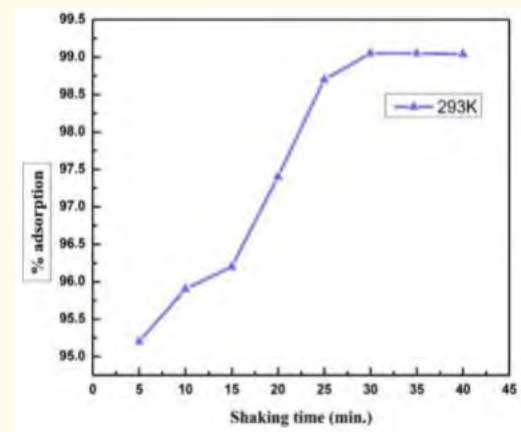

Figure 11: Plot for the maximum \% removal of $\mathrm{Cr}(\mathrm{III})$ at different time interval.

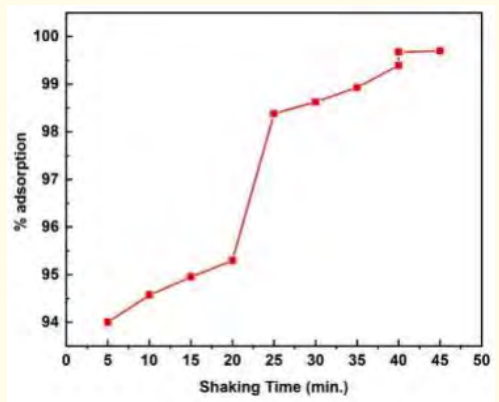

Figure 12: Plot for the maximum \% removal of $\mathrm{Cr}(\mathrm{VI})$ at different time interval.

\section{Application of pseudo second order kinetic model}

The most common and applicable model in previous studies were found to be Pseudo second order model, which is used to know the actual amount of adsorption on $\mathrm{AC} /$ monolith- $\mathrm{SiO}_{2}$ surface [27]. Whereas the equation used for the sorption process is given below.

$$
\frac{t}{q_{t}}=\frac{1}{k_{2} q_{e}^{2}}+\frac{1}{q_{e}} t
$$


Where qe denoted the adsorbed amount of $\mathrm{Cr}(\mathrm{VI})$ and $\mathrm{Cr}(\mathrm{III})$ at equilibrium time, qt is the amount adsorbed at time $t$ while $\mathrm{K}_{2}$ is the rate constant for the adsorption process. Graph obtained by plotting t/q against $t$ value of $\mathrm{R}^{2}$ which is shown in the Figures 13 and14. the result revealed that $\mathrm{R}^{2}$ value is much closer to unity and the calculated qe value from the pseudo second order model supported the experimental data for both $\mathrm{Cr}(\mathrm{VI})$ and $\mathrm{Cr}(\mathrm{III})$ and as shown in the Tables 2 and 3.

\begin{tabular}{|c|c|}
\hline Time (min.) & $\boldsymbol{t} / \boldsymbol{q t}\left(\boldsymbol{m i n} \cdot \mathbf{g ~ g}^{\mathbf{1}}\right)$ \\
\hline 1 & 0.38 \\
\hline 2 & 0.63 \\
\hline 3 & 0.81 \\
\hline 4 & 1.02 \\
\hline
\end{tabular}

Table 2: Data of pseudo second order kinetic model for $\mathrm{Cr}(\mathrm{III})$.

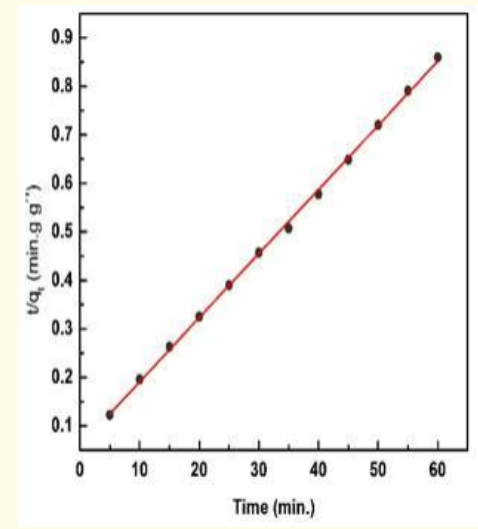

Figure 13: Pseudo second order plot for Cr(III).

\begin{tabular}{|c|c|}
\hline Time (min.) & $\boldsymbol{t} / \boldsymbol{q t}\left(\boldsymbol{m i n} . \boldsymbol{g ~ g}^{\mathbf{1}}\right)$ \\
\hline 1 & 0.47 \\
\hline 2 & 0.77 \\
\hline 3 & 1 \\
\hline 4 & 1.28 \\
\hline
\end{tabular}

Table 3: Data of pseudo second order kinetic model for $\mathrm{Cr}$ (VI).

\section{Intra-particle diffusion model}

The newly synthesized (AC/monolith-SiO ${ }_{2}$ ) exhibit greater porosity and high adsorption capacity due to pseudo monolithic architecture of composite. The large through pores accounts for the increased mass transfer kinetics and hence there is increased intra-particle diffusion. Enhance Rate of intra-particle diffusion and improved mass transfer kinetics is also due the presence of large number of pores on the surface of adsorbent. The intra particle diffusion model is frequently the rate determining step. In a first step the ions start movement towards the adsorbent form a layer around the solid surface by convection method. In second step, the ions reach to the surface of adsorbent form Figure 14. 


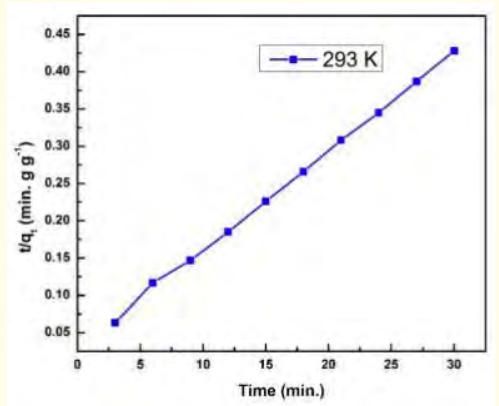

Figure 14: Pseudo second order kinetic model plot for $\mathrm{Cr}(\mathrm{IV})$.

Layer where stepwise adsorption of ions occurred. In a last step diffusion of adsorbate takes place inside the interior pores through intra particle diffusion and finds the active sites of in the interior pores. The following equation is used to determine the intra particle diffusion [36].

$$
q_{t}=R_{D} \sqrt{t}
$$

Where RD is the rate constant for the intra particle diffusion that is calculated from the slope of plot between qt verses $\mathrm{t}^{1 / 2}$ and $\mathrm{qt}$ is the intercept for the approximation of boundary layer of thickness. According to this model if intra particle diffusion occurs during adsorption process then a linear plot will be obtained and if the line passes from origin then it means that intra particle diffusion is rate controlling step. The data of intra particle diffusion of $\mathrm{Cr}(\mathrm{VI})$ and $\mathrm{Cr}(\mathrm{III})$ and is given in Table 3 and 4 and the process of adsorption is illustrated in Figure 15 and 16. The calculated values of Ci were 1.82 and $2.24 \mathrm{mg} / \mathrm{L}$ for $\mathrm{Cr}(\mathrm{VI})$ and $\mathrm{Cr}$ (III) respectively which confirms intra particle diffusion.

\begin{tabular}{|c|c|}
\hline $\boldsymbol{t}^{\mathbf{1 / 2}}$ & $\boldsymbol{q} \boldsymbol{t}$ \\
\hline 0.5 & 2.6 \\
\hline 1 & 3.2 \\
\hline 1.5 & 3.7 \\
\hline 2 & 3.9 \\
\hline 2.5 & 4.48 \\
\hline
\end{tabular}

Table 4: Data of intra particle diffusion model for $\operatorname{Cr}(\mathrm{III})$.

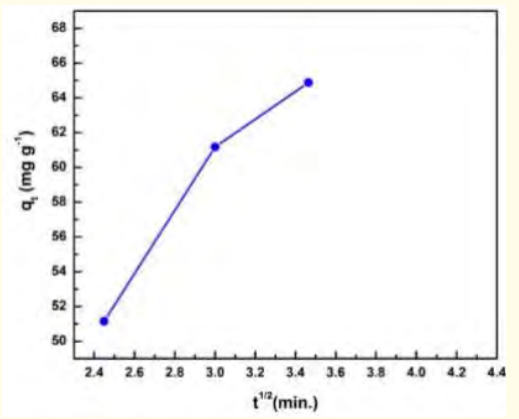

Figure 15: Plot of intra particle diffusion model for $\mathrm{Cr}(\mathrm{III})$. 


\begin{tabular}{|c|c|}
\hline $\boldsymbol{t}^{\mathbf{1 / 2}}$ (min.) & qt (mol. min.) \\
\hline 0.5 & 2.1 \\
\hline 1 & 2.57 \\
\hline 1.5 & 2.99 \\
\hline 2 & 3.11 \\
\hline 2.5 & 3.56 \\
\hline
\end{tabular}

Table 5: Intra particle diffusion model for $\mathrm{Cr}$ (IV).

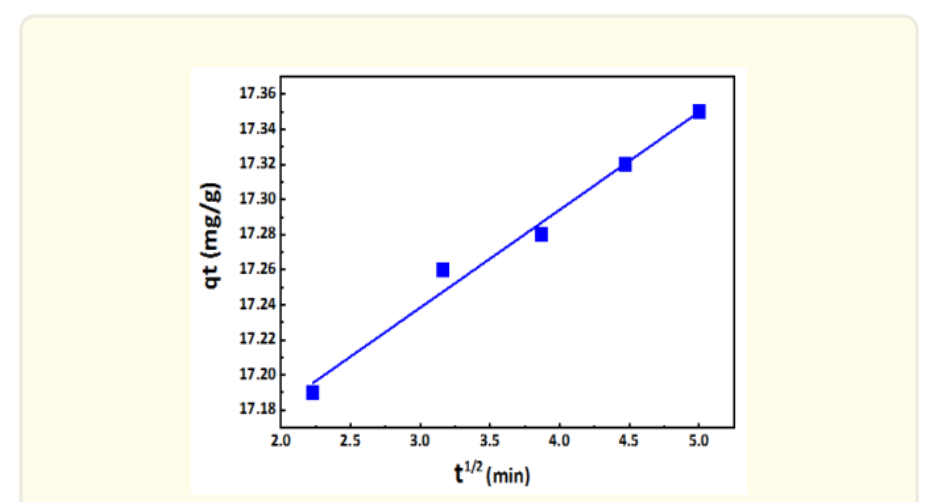

Figure 16: Plot of the intra particle diffusion model for $\mathrm{Cr}(\mathrm{VI})$.

\section{Thermodynamic Study}

The influence of temperature on the removal of $\mathrm{Cr}$ (IV) and $\mathrm{Cr}$ (III) ions from a single solution was investigated in the temperature ranges of 293-313K. The linear relationship of adsorption with temperature (Figure 17a) shows that it is an endothermic process [37].

The following equations were used to determine the thermodynamic parameters [38].

$$
\begin{gathered}
\Delta G=-R T \ln K_{c} \\
\ln K=\frac{\Delta S}{R}-\frac{\Delta H}{R T} \\
\Delta G=\Delta H-T \Delta S
\end{gathered}
$$

The $\Delta \mathrm{G}$ values were -50.02 and $-49.62 \mathrm{~kJ} \mathrm{~mol}^{-1}$, for $\mathrm{Cr}(\mathrm{VI})$ ions and $\mathrm{Cr}$ (III) ions respectively, which show spontaneous adsorption of $\mathrm{Cr}(\mathrm{VI})$ and $\mathrm{Cr}$ (III) ions on to AC surface [39]. $\Delta \mathrm{H}$ was $44.18 \mathrm{~kJ} \mathrm{~mol}^{-1}$ for $\mathrm{Cr}$ (VI) and $39.55 \mathrm{~kJ} \mathrm{~mol}^{-1}$ “for Cr(III) ions, are showing the endo-

\begin{tabular}{|c|c|c|c|c|c|c|}
\hline \multirow[t]{2}{*}{ Temp.(K) } & \multicolumn{2}{|c|}{$\Delta G\left(\mathrm{kJmol}^{-1}\right)}$. & \multicolumn{2}{|c|}{$\Delta H\left(\mathrm{kJmol}^{-1}\right)}$. & \multicolumn{2}{|c|}{$\Delta S\left(\mathrm{kJmol}^{-1} \mathrm{~K}^{-1}\right)$} \\
\hline & $\operatorname{Cr}(\mathrm{III})$ & $\mathrm{Cr}(\mathrm{VI})$ & $\operatorname{Cr}(\mathrm{III})$ & $\mathrm{Cr}(\mathrm{VI})$ & $\operatorname{Cr}(\mathrm{III})$ & $\mathrm{Cr}(\mathrm{VI})$ \\
\hline 293 & -50.02 & -49.62 & \multirow{3}{*}{44.18} & \multirow{3}{*}{39.55} & \multirow{3}{*}{152} & \multirow{3}{*}{139.88} \\
\hline 303 & -52.45 & -51.07 & & & & \\
\hline 313 & -57.09 & -55.97 & & & & \\
\hline
\end{tabular}
thermic nature of adsorption [40]. The $\Delta \mathrm{S}$ (152 $\mathrm{J} \mathrm{mol}^{-1} \mathrm{~K}^{-1}$ for $\mathrm{Cr}(\mathrm{VI})$ and $139.88 \mathrm{~mol}-1 \mathrm{~K}-1$ for $\mathrm{Cr}(\mathrm{III})$ ions) determined from lnk against 1/T (Figure 17 b) show enhanced entropy which reflects sorbate/sorbent complexation stability [41, 42].

Table 6: Variation of adsorption equilibrium of $\mathrm{Cr}$ (III) ions and $\mathrm{Cr}$ (VI). 

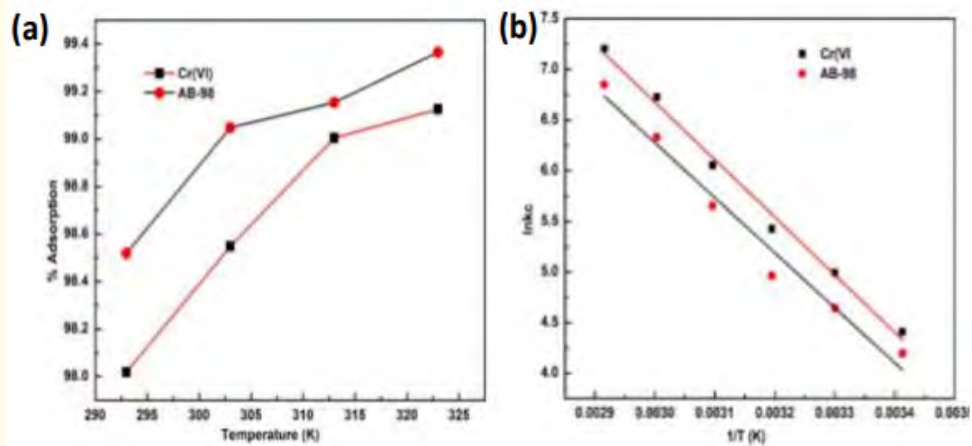

Figure 17 (a): Effect of temperature on the adsorption of $\mathrm{Cr}$ (III) ionsion and $\mathrm{Cr}$ (VI) ions and (b) Variation of adsorption equilibrium of $\mathrm{Cr}(\mathrm{III})$ and $\mathrm{Cr}(\mathrm{VI})$ ions with temperature.

\section{Conclusion}

The present work was designed to synthesis pseudo-monolith silica particle by sophisticated sol-gel procedure and their modification with activated carbon to form of composite for the adsorption of $\mathrm{Cr}$ (III) and $\mathrm{Cr}$ (VI) ions from aqueous media. 3-Aminopropyletriethoxysilane was used as the propagating legend and the formation of the newly synthesized composite was confirmed by FE-SEM and XRD characterization. The maximum adsorption capacity of the media to remove the metal ions such as $\mathrm{Cr}$ (III) and $\mathrm{Cr}(\mathrm{VI})$ was strongly controlled by metal concentration, contact time with adsorbent, adsorbent dosage and $\mathrm{pH}$ were studied on the adsorption rate. The results reveal that the adsorption was endothermic, spontaneous and feasible. The entropy revealed the stability of adsorbate/adsorbent stability.

\section{References}

1. BR James., et al. "Oxidation-reduction chemistry of chromium: Relevance to the regulation and remediation of chromate-contaminated soils". Soil and Sediment Contamination 6 (1997): 569-580.

2. E Plunkett. Handbook of Industrial Toxicology, Edward Arnol d Publication Co, Inc., USA (1987).

3. SM Hasany., et al. "Investigation of sorption of Hg (II) ions onto coconut husk from aqueous solution using radiotracer technique". Radiochimica Acta 91 (2003): 533-538.

4. K Panday., et al. "Removal of Cr (V1) from aqueous solutions by adsorption on fly ash-wollastonite”. Journal of Chemical Technology and Biotechnology. Chemical Technology 34 (1984): 367-374.

5. M Foldesova., et al. "Adsorption and desorption of $\mathrm{Cr}$ (III) on natural and chemically modified Slovak zeolites". Journal of Radioanalytical and Nuclear Chemistry 245 (2000): 435-439.

6. K Low., et al. "Chromium (III) Sorption Enhancement Through NTA-Modification of Biological Materials". Bulletin of environmental contamination and toxicology 58 (1997): 380-386.

7. N Khalid., et al. "Adsorption behavior of rice husk for the decontamination of chromium from industrial effluents". Journal of radioanalytical and nuclear chemistry 240 (1999): 775-781.

8. S Hasany and M Chaudhry. "Fixation of Cr (III) traces onto Haro river sand from acidic solution". Journal of radioanalytical and nuclear chemistry 230 (1998): 11-15.

9. K Low., et al. “Column study on the sorption of Cr (VI) using quaternized rice hulls”. Bioresource Technology 68 (1999): 205-208.

10. H Aslani., et al. "Hexavalent chromium removal from aqueous solution using functionalized chitosan as a novel nano-adsorbent: modeling and optimization, kinetic, isotherm, and thermodynamic studies, and toxicity testing". Environmental Science and Pol- 
lution Research 25.20 (2018): 20154-20168.

11. M Chebeir., et al. "Emerging investigators series: frontier review: occurrence and speciation of chromium in drinking water distribution systems". Environmental Science: Water Research \& Technology 2 (2016): 906-914.

12. MH Dehghani., et al. "Removal of noxious Cr (VI) ions using single-walled carbon nanotubes and multi-walled carbon nanotubes". Chemical Engineering Journal 279 (2015): 344-352.

13. M Barakat. "New trends in removing heavy metals from industrial waste water". Arabian journal of chemistry 4 (2011): 361-377.

14. N Martone., et al. "Determination of chromium species in dietary supplements using speciated isotope dilution mass spectrometry with mass balance". J Agric Food Chem 61.41 (2013): 9966-9976.

15. Z Wan., et al. "Concurrent reduction-adsorption of chromium using m-phenylenediamine-modified magnetic chitosan: kinetics, isotherm, and mechanism”. Environmental Science and Pollution Research 25 (2018): 17830-17841.

16. A Vengosh., et al. "Origin of hexavalent chromium in drinking water wells from the piedmont aquifers of North Carolina". Environmental Science \& Technology Letters 3 (2016): 409-414.

17. WH Organization (2017) Guidelines for drinking-water quality: first addendum to the fourth edition.

18. H Li., et al. "Preparation and Cr (VI) removal performance of corncob activated carbon". Environmental Science and Pollution Research 25.21 (2018): 20743-20755.

19. Z Ali., et al. "Functionalized nanospheres for efficient sequestration of cadmium ions". RSC advances 4 (2014): 50056-50063.

20. AB Fuertes., et al. "One-step synthesis of silica@ resorcinol-formaldehyde spheres and their application for the fabrication of polymer and carbon capsules". Chemical Communications 48 (2012): 6124-6126.

21. KH Lo., et al. "Enhanced reductive dechlorination of trichloroethene with immobilized Clostridium butyricum in silica gel". Chemosphere 238 (2020): 124596.

22. KT Chung. "The significance of azo-reduction in the mutagenesis and carcinogenesis of azo dyes". Mutation Research 114.3 (1983): 269-281.

23. MK Uddin. "A review on the adsorption of heavy metals by clay minerals, with special focus on the past decade". Chem Eng J 308 (2017): 438-462.

24. AS Ayangbenro and 00 Babalola. "A new strategy for heavy metal polluted environments: a review of microbial biosorbents". International journal of environmental research and public health 14.1 (2017) 4: 94.

25. I Khan., et al. "Investigation of the photocatalytic potential enhancement of silica monolith decorated tin oxide nanoparticles through experimental and theoretical studies". New J Chem 44 (2020): 13330-13343.

26. VK Gupta., et al. "Chromium removal from water by activated carbon developed from waste rubber tires". Environmental Science and Pollution Research 20.3 (2013): 1261-1268.

27. SU Jan., et al. "Removal of azo dye from aqueous solution by a low-cost activated carbon prepared from coal: adsorption kinetics, isotherms study, and DFT simulation". Environmental Science and Pollution Research 28.8 (2021): 10234-10247.

28. I Langmuir. "The adsorption of gases on plane surfaces of glass, mica and platinum". Journal of the American Chemical society 40 (1918): 1361-1403

29. HFreundlich and H Hatfield. Colloid and capillary chemistry, Methuen and Co, Ltd., London (1926): 110-114.

30. MB Desta. "Batch sorption experiments: Langmuir and Freundlich isotherm studies for the adsorption of textile metal ions onto teff straw (Eragrostis tef) agricultural waste". Journal of thermodynamics (2013).

31. D Mohan., et al. "Adsorption of arsenic using low cost adsorbents: guava leaf biomass, mango bark and bagasse". Indian Academy of Sciences (2019).

32. J Zhang., et al. "Sludge-based biochar activation to enhance Pb (II) adsorption”. Fuel 252 (2019): 101-108.

33. F Fajarwati., et al. "Adsorption Study of Methylene Blue and Eriochrome Black T Dyes on Activated Carbon and Magnetic Carbon Composite". IOP Conference Series: Materials Science and Engineering, IOP Publishing (2019): 012025.

34. MD Stout., et al. "Hexavalent chromium is carcinogenic to F344/N rats and B6C3F1 mice after chronic oral exposure". Environ 
Health Perspect 117.5 (2009):716-722.

35. A Sarı., et al. "Adsorption of Pb (II) and Cr (III) from aqueous solution on Celtek clay". J. Hazard. Mater 144.1-2 (2007): 41-46.

36. W Cheung., et al. "Intraparticle diffusion processes during acid dye adsorption onto chitosan”. Bioresour Technol 98.15 (2007): 2897-2904.

37. R Ahmad., et al. "Removal of Tm (III) ions from aqueous solution using PAN-incorporated sol-gel matrices". Radiochimica Acta 95 (2007): 451-457.

38. Z Ali., et al. "Organic-inorganic hybrids: an efficient extractant of environmental mercury ions". Materials Research Express 5 (2018): 075007.

39. Y Chang., et al. "Thermodynamic parameters for adsorption equilibrium of heavy metals and dyes from wastewaters: Research updated". Bioresour. Technol 222 (2016): 513-516.

40. H Kim., et al. "Characterization of adsorption enthalpy of novel water-stable zeolites and metal-organic frameworks". Scientific reports 6 (2016): 1-8.

41. M Peydayesh., et al. "Assessing the binding performance of amyloid-carbon membranes toward heavy metal ions". Langmuir 35 (2019): 4161-4170.

42. Z Ali., et al. "The use of functionalized aerogels as a low level chromium scavenger". Microporous and Mesoporous Materials 203 (2015): 8-16.

Volume 2 Issue 1 January 2022

(c) All rights are reserved by Saeed Ullah Jan., et al. 